\title{
MEMÓRIA, NARRATIVA E AS HISTÓRIAS DO MUNDO ${ }^{1}$
}

\author{
Ana Luiza Carvalho da Rocha e Cornelia Eckert
}

\section{O desterro das lembranças}

No desvendamento de diferentes modalidades das sociedades humanas configurarem o controle simbólico do tempo, as ciências humanas trataram, mais recentemente, de desconstruir o tempo por intermédio de sua dimensão interpretativa. Seja como espaço de construção de uma inteligência narrativa que encerra a experiência de duração ${ }^{2}$, reino da imaginação criadora; seja como fenômeno que participa das estruturas antropológicas do imaginário e de sua topologia fantástica, nos arranjos que esta engendra entre vida e matéria ${ }^{3}$.

Uma vez que se reconheça os limites da separação ontológica entre ambas as instâncias, além do paroxismo que encerram tais atos humanos de rememoração, não se trata mais, na linha de argumentação aqui apontada, de refletir sobre a memória apenas, e tão somente, sob os efeitos de imagens-vestígios. É a força interpretativa reconhecida à memória como espaço de construção de conhecimento que desponta como fenômeno a ser aqui aprofundado, tratando-se aí de reconhecer e compreender as tradições históricas, sociais e culturais que carregam e marcam de suas configurações.

Nestes termos, os jogos da memória explicitariam uma ação inteligente singular do sujeito humano sobre o mundo nas busca de um princípio de causalidade (formal e material) que possa enquadrar, de forma inseparável, vida e matéria. A memória compreendida como um topos espaço fantástico, lugar de extraversão e introversão de uma linguagem arbitrária de símbolos, e coordenada, no plano da imaginação criadora, por esquemas de pensamento, evocaria, portanto, os diferentes procedimentos interpretativos-narrativos que dão sentido aos arranjos entre vida e matéria, reunindo-as de forma inseparável.

Sob os efeitos do desmoronamento dos mapas intelectuais do séc. XIX e da perda de sua aura, foi W. Benjamin (1892-1940) quem primeiro teve o mérito de

\footnotetext{
${ }^{1}$ Trabalho apresentado no $23^{\circ}$ ENCONTRO ANUAL DA ANPOCS; Caxambú, MG, Brasil, de 19 a 23 OUTUBRO DE 1999; GT 01 Biografia e Memória Social.

${ }^{2}$ Cf. RICOEUR, P. Tempo e Narrativa. Volumes I, I e III. São Paulo, Papirus, 1994 e El tiempo y las filosofías. Paris, Unesco/ Salamanca, Ediciones Sígueme, 1979.

${ }^{3}$ Cf. G. DURAND, Cf. G. DURAND, Les structures anthropologiques de l'imaginaire, Paris, Dunod, 1984, cuja obra segue a linhagem direta dos estudos bachelardianos sobre a duração, cf. G. BACHELARD, La dialectique de la durée, Paris, PUF.
} 
confrontar-se, ainda que sob a atmosfera do desencantamento do mundo, com o dilema do esquecimento. Segundoeste autor, no mundo moderno, a situação agonizante das tradições e a morte da narrativa tornava-se uma ameaça. Assim, segundo este autor, no mundo moderno, abreviando-se a narrativa, substituindo-a por uma historiografia na intenção de atingir “o plano divino da salvação", o rosto da morte acabaria referido ao mundo dos vivos, privando-se a memória de sua força narrativa, justamente esta que autorizaria a humanidade, em parte, a reparar os ultrajes do tempo. Nas palavras do mestre, "a memória é capacidade épica por excelência".

Embora sua intenção fosse de investir no entendimento do substrato racional que subjaz este fenômeno, Benjamin, ao ressaltar o valor da narração como locus central dos jogos da memória ${ }^{4}$ reúne aos atos da razão as instâncias do sentimento, da intuição e do movimento ${ }^{5}$. Em particular, ao tecer uma crítica ao conceito de duração em Bergson, Benjamin ressalta que o pensamento bergsoniano, ao afastar-se da história na compreensão dos jogos da memória, suprime a morte, excluindo-se a possibilidade de compreendê-los como fenômeno que acolheria a tradição ${ }^{6}$, além de pretender auferirlhes o ideal de dedução absoluta do mundo das coisas.

Neste ponto, o tema do "fantasma do esquecimento", tão caro a obra de Benjamin, anuncia, de forma comovente, o sentimento de "crise da civilização" que se manifesta na crise epistemológica das "ciências do homem" geradas no mundo contemporâneo.

\section{A mística da morte da narrativa nos jogos da memória}

Ao longo das imensas rupturas e descontinuidades provocadas por revoluções tecnológicas e científicas do séc. XX, não é ao acaso, portanto, que se constata, hoje, que os estudos da memória, ao encaminharem-se para uma reflexão sobre a vida e a matéria, retornam ao ato de narrar um valor simbólico de construção de sentido de uma história vivida entre tantas outras para serem vividas.

De fins do séc. XIX até os dias de hoje, o sensorialismo e os trabalhos de

\footnotetext{
${ }^{4}$ Os textos de W. BENJAMIN utilizados na composição deste artigo foram "Sobre alguns temas em Baudelaire". In: Charles Baudelaire, um lírico no auge do capitalismo. Obras escolhidas volume III. SP, Ed. Brasiliense, 1990, "O Narrador" e "O Surrealismo". In: Coleção Os Pensadores, São Paulo, Ed. Abril, 1978.

${ }^{5}$ Cf. M. SANTOS "O pesadelo da amnésia coletiva, um estudo sobre os conceitos de memória, tradição e traços do passado. "In Revista Brasileira de Ciências Sociais, n 3, ano 8, outubro de 1993, ANPOCS 23, p.83.

${ }^{6}$ Cf. BENJAMIN, 1990, op. cit., p.137.

7 Segundo, S. H. BORELLI, "Memória e temporalidade: diálogo entre Walter Benjamin e Henri Bergson". In: Revista Margem. Faculdade de Ciências Sociais - PUC - SP, 1992, p. 90: "Para Benjamin, portanto, onde existe experiência restaurada, existe a conjunção inevitável entre passado individual e referenciais coletivos"
} 
miniaturização do mundo atribuídos aos jogos da memória, assim como a viscosidade confusional designada ao lugar das lembranças do passado na vida presente, despontam, via de regra, como valores antagonistas à destruição, em escala mundial, de povos e culturas. Para se entender a reconciliação da consciência ocidental com valores de "resistência" aos jogos da memória, nos dias de hoje, há que se ter presente o processo de desencaixe espaço-tempo que tem sido apontado como fenômeno singular das sociedades contemporâneas.

Ao longo do séc. XX, o confronto entre presente e passado, reunidos num mesmo espaço pelas curvaturas do tempo da grande "aldeia global" tem impulsionado as ciências humanas ao reconhecimento das rupturas de uma temporalidade que parecia linear, contínua e progressista. O grande desafio agora é a aceitação de um tempo múltiplo onde os jogos da memória sugerem, a todos quantos deles participam, uma relação reflexiva com a trajetória histórica do sujeito e do coletivo que professam.

Progressivamente, a consciência ocidental critica uma concepção que prioriza a causalidade histórica para o estudo da memória, agora, mais do que antes associado a uma "longue durée" ${ }^{8}$, uma vez que ela é constrangida ao reconhecimento de que o tempo está contido na "imagem dialética" 9 entre "despertar" e "recordar". Ao passado é atribuído, então, ume estatuto de conhecimento a partir de um presente conceitualizado, sendo a prática da rememoração re-situada, portanto, no corpo da narrativa dos sujeitos sociais.

No interior da erosão do mito do Progresso, os estudos da memória tornaram-se, assim, por vezes, propícios ao "reinvestimento mitológico" onde não só triunfam os valores e as imagens da intimidade, de uma certa nostalgia do "eu profundo", mas despontam como referenciais na interpretação/compreensão dos temas da alteridade que regem as relações entre a vida humana e a matéria de suas ações no mundo.

Em decorrência, o ato de rememorar transforma-se, assim, numa força reinventiva do tempo do mundo no qual gravita toda a sociedade humana, agora numa escala de vida planetária. A memória adquire densidade e espessura, referida que está às suas camadas de duração, base sobre a qual se erigiu a humanidade em sua capacidade refletir frente ao que lhe é transmitido socialmente, ao mesmo tempo "alma santa", "vítima" e "carrasco". O estudo da memória torna-se, portanto, uma porta de acesso ao

\footnotetext{
${ }^{8}$ A respeito ver LE GOFF, J. NORA, P. "Les lieux de la mémoire", Paris, Gallimard e LE GOFF, Jacques. História e memória. Campinas, ED. UNICAMP, 1990.

${ }^{9}$ Cf. comentários de BOLLE, 1994, op. cit. "a imagem dialética não se opõe em termos absolutos à imagem onírica, mas guarda dela um resíduo mítico".
} 
entendimento das curvaturas do tempo que configuram o próprio espaço das culturas contemporâneas.

Desta forma, diferentemente do que, nos séculos precedentes, a sociedade contemporânea, hoje, se debate com a herança dos paradigmas que geraram a noção de pessoa moderna, os postulados do individualismo e "sua epopéia humanitária e progressista" ${ }^{10}$. Da concepção puramente cosmológica do movimento temporal tal qual apresentada por Aristóteles, das aporias de Santo Agostinho sobre a distentio animi, do dogmatismo doutrinário de Sto Tomas de Aquino e do idealismo das formas a priori de entendimento e de sensibilidade em Kant ao racionalismo positivista que impregnou a civilização ocidental, transmutam-se novos valores epistêmicos que propõe questionar, desde suas origens, a universalização da temporalidade cristã, em cujo trajeto, a figura tradicional do homem, contraposta ao homem da civilização, cresceu e se avolumou como "uma espécie de anti-história". 11

Para se prosseguir no desvendamento de parte deste processo de universalização da temporalidade cristã e de reconciliação da consciência ocidental com a força narrativa da memória como ato que autoriza as sociedades humanas a "reparar os ultrajes do tempo ${ }^{12}$, é que se aponta aqui para o pressuposto antropológico que reconhece a multiplicidade antagonista que encerra a figura do homem, ou seja, para a importância de se abandonar a perspectiva de uma explicação causal única para o fenômeno do tempo que encobre o estudo da memória.

Segundo a tese que se apresenta aqui, a memória se configura como inteligência narrativa ${ }^{13}$ uma vez que por seu intermédio o pensamento humano, enquadrando um tempo ondulante e lacunar, consolida-o como duração da matéria. Um complexo e profundo fenômeno de arranjo de estruturas espaço-temporais (tempo do mundo e o tempo pensado) que remetem a uma hierarquia na essência do próprio ser, e que não pode ser reduzido a pura intuição do tempo, pois este lhe escapa no triunfo de um tempo reencontrado, logo negado. ${ }^{14}$

\footnotetext{
10 Ver a respeito os comentários de G. DURAND, 1979, op.cit., Cap. Le XXe siècle et le retour d'Hérmes.

${ }^{11}$ Cf. G. DURAND. 1979, op. cit., p. 20.

${ }^{12}$ Cf. G. DURAND, op. cit., 1984, p.275.

${ }_{13}$ Cf. P. RICOEUR, Tempo e Narrativa, São Paulo, Papirus, 1994, Vol I.

14 A tese que se apresenta aqui é herdeira direta do pensamento bachelardiano e seus estudos sobre a duração, cf. La dialectique de la durée, Paris, PUF, 1989 e de filho legítimo, G. DURAND, em seus estudos sobre as estruturas antropológicas do Imaginário, op.cit.. Ambos os pensamentos dos autores constituem chaves-mestras para uma releitura da obra de P. Ricoeur, supra, em seus 3 volumes e a obra que os completa, O si-mesmo como um outro, São Paulo, Papirus, 1994.
} 
Ao se conceber a memória como força de arranjo de um todo a partir de um fragmento vivido, como a pequena Madalena do Temps perdu, atinge-se a idéia de que a vida não segue o devir cego da matéria, mas reconcilia-se com ela em sua capacidade de criação e modelagem ${ }^{15}$, pois um mero fragmento de existência pode resumir e simbolizar a totalidade do tempo reencontrado ${ }^{16}$.

Neste sentido, é através do campo da investigação antropológica, eternamente construindo para dar conta da compreensão, ao mesmo tempo, universal e singular das experiências humanas, e onde o próprio fazer antropológico se situa, que se procura aqui desfazer as teses reducionistas que não atingem a compreensão das curvaturas do tempo da memória e, portanto, não vislumbram que é no interior dos seus jogos que é possível, ao sujeito humano, sempre e eternamente, reintegrar um tempo perdido, reconciliando vida e matéria.

Isto porque, ao longo de décadas, a matriz disciplinar da Antropologia, tem insistido no fato de que nas civilizações de práticas não-ocidentais o tempo é vivido e pensando através do continuum da memória, salvaguardado na tradição e perpetuado, em suas camadas superficiais ou profundas, segundo o pertencimento da pessoa humana, múltipla e plural, a tal ordem de criação. Para o "homem da tradição", portanto, diferentemente do "homem da civilização", rememorar traduz-se por uma atitude espiritual que envolve diretamente rituais cotidianos que são fundamentais para que a ameaça de esquecimento seja dissipada ${ }^{17}$. Atos rituais (sagrados) e atos cotidianos (profanos) são em si mesmo, unos, configurando-se a memória como enthousiasmos ${ }^{18}$.

Sem dúvida, esta perspectiva de se viver o tempo aderindo ao ritmo de sua própria matéria ondulatória, choca-se com o processo de construção e demarcação de uma nova temporalidade e épistémè, das quais muitos de nós, antropólogos, para o pior ou o melhor, somos herdeiros bastardos. Ou seja, a épistèmé clássica, responsável pela “desfiguração da visão do homem" no Ocidente judeu-cristão e pela gênese da concepção de pessoa moderna pela via da desacralização do fenômeno da memória.

\footnotetext{
${ }^{15}$ Seguem-se aqui as críticas pertinentes de J. PIAGET, "Sabedoria e ilusões da filosofia”, In: Séne $O s$ Pensadores, Ed. Abril, 1978, a respeito do pensamento kantiano e bergsoniano em suas reflexões sobre o tempo.

${ }^{16}$ Cf. G. DURAND, 1979, op. cit.

${ }^{17}$ M. ELIADE, em sua obra clássica, Le mythe de l'éternel retour”, Paris, Les Essais, 1982, analisa aqui o tempo como sagrado por sua qualidade de Eterno Retorno, conquistado na permanência dos rituais que eternizam o presente por pressupostos cosmológicos.

${ }^{18}$ Segundo L.F. DIAS DUARTE, op. cit., p.31:"A 'memoricidade' é assim em primeiro lugar 'possessão' - enthousiasmos. E enquanto 'possessão’ é também - repetindo a dualidade das experiências religiosas - 'iniciação', treinamento ritual, organização 'litúrgica”".
} 


\section{A memória e seus duplos, a poeira do tempo}

Neste ponto em que a reflexão se apresenta, vale a pergunta: a Antropologia, em suas tentativas para entender o paradoxo criador que é o homem, atinge as condições epistemológicas adequadas, na linha de um "pensare doble", para operar com conhecimento da memória a partir de uma idéia de tempos múltiplos e sobrepostos? Quais os funções que cumprem as duas premissas básicas desta matriz disciplinar - a comparação e a relativização - na resolução positiva deste questionamento?

Todos os antropólogos conhecem, na linha do anthropological blues, o desafio de traduzir, nos termos da sociedade ocidental (da linearidade da escrita e do discurso científico), as variadas modalidades simbólicas de controle do tempo apresentadas pela diversidade das sociedades humanas ${ }^{19}$. Como, por exemplo, tornar inteligível a interpenetração do acontecimento e da estrutura para os antropólogos que já habituados à axiomática separação entre história e mito ${ }^{20}$

Seguindo-se a trilha de inúmeros estudos etnográficos sobre a ideologia moderna, sabe-se que a base da "personalidade" ocidental reside justamente na separação do mundo e do eu, sendo a memória freqüentemente referida œmo um fenômeno que não participa do mundo, não tem nenhuma "espessura", nem "densidade relativa à permeabilidade entre as esferas coetâneas do humano e do divino" 21 . É, portanto, a partir da conversão progressiva de um eu múltiplo e diverso, paradigmático da figura tradicional de homem, e de suas camadas de duração, à vacuidade da Consciência, expressa na fórmula "Eu penso... logo existo", que se pode reconhecer a moderna conceitualização da memória como tempo subjetivado.

O tempo variável torna-se, por assim dizer, o produto historicizado de funções de coordenação que o sujeito do Cogito, sede da Consciência, lhe impõem, e onde instrumentos de medida se tornaram possíveis pela dèmarche simbólica de intervalos vazios e opacos, unificados formalmente pelo pensamento científico agnóstico ${ }^{22}$.

O tempo, então, se configura, na Modernidade triunfante, numa atividade

\footnotetext{
19 Segundo G. DURAND, 1979, op. cit., é necessário inverter os termos da famosa prescrição délfica, "Conhece incialmente os deuses, conhece teu universo cósmico e cultural e tu te conhecerás a ti mesmo", degradada numa interpretação de neutralidade axiológica progressiva e unidimensional do sujeito do Cogito, para outra modalidade de frase: "Conhece-te a ti mesmo, e tu conhecerás o cosmo e os deuses".

${ }^{20}$ Cf. RAMOS, Rita Alcida. Memórias Sanumá. Espaço e tempo em uma sociedade Yanomami. Brasília, Marco Zero, UNB, 1990, p.179.

${ }^{21}$ Cf, G. DURAND, op. cit., 1979.

${ }^{22}$ DOSSE. 1996. Cf. comentários P. RICOEUR, 1994, o tempo regulado do calendário torna-se o, enfim, intermediário entre o tempo vivido e o tempo cósmico. Essa modalidade simbólica de controle de tempo, o calendário, cosmologiza o tempo vivido e humaniza o tempo cósmico.
} 
humana singular que consiste em "fazer o tempo", associando-se ao princípio fundamental de conquista do mundo. Pensar o tempo, enquadrá-lo, significa alinhar historicamente a cronologia existencial da vida ${ }^{23}$. A decifração do tempo não contempla mais um pensamento simbólico que adere simpaticamente às coisas e aos lugares, na busca do desvendamento de seu sentido ${ }^{24}$. Sob o signo do esfacelamento da gnose do tempo tanto quanto da gnose do espaço, desfigura-se progressivamente não apenas a figura do homem, mas a função fantástica da memória, "reserva infinita de eternidade contra o tempo", ${ }^{25}$ sujeita ao dinamismo da consciência ou a condição de imagem miniatura do mundo.

Tal é o estatuto que assume as reflexões sobre o tempo sob o manto do Iluminismo $^{26}$. O tempo não mais diz respeito às relações entre o homem e cosmos, mas à noção de Sujeito histórico, ético-moral. A figura humana ascende, enfim, ao estatuto de um micro-universo, torna-se, finalmente, sujeito absoluto e autônomo da razão que atua no lugar do próprio Tempo.

Sem dúvida, esse trajeto sinistro do "homem da civilização" 27 que negligencia à memória as propriedades de um espaço fantástico, e onde a imagina ção criadora pode dirigir suas obra contra a Morte e o Destino, não se afirma como a absoluta vitória do tempo linear e progressista sobre outras modalidades simbólicas de controle do tempo na civilização do Ocidente extremo.

Já em fins do séc. XIX, a experiência proustiana romântica do "tempo reencontrado", emergindo da "estratificação de múltiplas renarrações", nos termos benjaminianos, desfazia as teses reducionistas que não conseguiam atingir, com suas teorizações, as curvaturas do tempo da memória. Na consciência romântica do séc. XIX, na contramão das consolidações positivistas da história que substituíram a velha ordem teológica e metafísica, os meandros cavernosos da memória evocavam a união do homem com o seu destino mortal, contrapondo-se às imagens messiânica e progressista do tempo, permitindo que, em plena era moderna, em meio às suas

\footnotetext{
${ }^{23}$ Cf. G. Durand, 1979, op. cit., p. 44

${ }^{24}$ A respeito, cf. FOUCAULT, Les mots et les choses, Paris, Gallimard.

${ }^{25}$ Cf. G. DURAND, Les structures anthropolgoiques de l'imaginaire. Paris, Dunod, 1984.

${ }^{26}$ DIAS DUARTE, 1983: 36 e 37.

${ }^{27}$ Segundo G. DURAND, 1979, Figures mythiques, op,. cit., o contraponto intimista se fazia sentir já no séc. XVIII no Iluminismo, com J.J. ROUSSEAU, face ao mito progressista que iria consumir lentamente o período pós-revolucionário, encontrando seu "refúgio" no séc. XIX, século do alcoolismo e do ideal heróico da produção industrial, e sua expressão decadente na atual sociedade de consumo, no séc. XX.
} 
transformações, a figura do homem “permaneça humana”. ${ }^{28} \mathrm{Em}$ Baudelaire, Valléry, Proust, a memória assume um papel redentor da queda moral da figura humana presente ao ideal prometéico do Ocidente moderno, uma vez que por seu intermédio as situações e os seus valores iniciais são re-invertidos, numa progressão dramática.

Assim é que, no séc. XIX, poetas, cronistas e memorialistas aderiram aos encantos de Mnemosyne, à sua fascinação onírica, religiosa, estética ou patológica. Tais autores, vale lembrar, não tinham por intenção desafiar o ideal prometéico do progresso técnico da sociedade industrial e de suas esperanças messeânicas; suas obras, entretanto, protegeram a consciência ocidental de suas contradições mais profundas. As imagens noturnas e os mitos da intimidade e da introspecção veiculados por suas obras, em fins do séc. XIX, tornaram-se o contraponto ao "culto da Razão", ao sujeito ético e moral da história, na sua luta heróica e diurna para domesticar o tempo e a morte, sob o ritmo dos relógios e dos apitos de fábricas. ${ }^{29}$

Portanto, é através da supervalorização da interioridade do tempo psicológico, que a "ideologia moderna" atribuiu uma dimensão unificadora à consciência nos jogos da memória, delegando ao sujeito do Cogito a ação de mediar o tempo do mundo e dos acontecimentos $^{30}$. Ironicamente, a ideologia moderna gerou no seu ventre, ao mesmo tempo, o culto romântico à memória não só como processo restrito a subjetivação do sujeito, mas como espaço de reinversão das situações e valores iniciais de um século de filosofias da história, de evolucionismo e de progressismos, tal qual aparece na obra de Baudelaire, comentada por Benjamin ${ }^{31}$.

\section{A dialética das "épistèmés”, rupturas a insularidade do tempo progessista}

Na proto-história da ciência antropológica, o quadro epistêmico do final século XIX, foi rico em deslizar das estruturas elementares do evolucionismo para a gestação de uma nova concepção da pessoa no contexto da duração histórica. Da mesma forma, o pensamento da École de l'Année Sociologique, foi fértil em exemplos a respeito das

\footnotetext{
28 A propósito, ver a obra de G. Durand, Figures mythiques et visages de l'ouvre, Paris, Berg International, 1979, em especial, o Cap. VIII, Les mythes et symboles de l'intimité au XXIe siècle.

${ }^{29}$ Cf. G. DURAND, 1979, op. cit., p. 41

${ }^{30}$ Cf. DIAS DUARTE, op. cit., p. 44 : "Pode-se afirmar, com propriedade, que o historicismo, por exemplo, formulou os parâmetros de uma consciência, onde a memória assume uma posição externa e factual, Da mesma forma, a nascimento da psicanálise engendra-se no momento em que atribui ao inconsciente esta representação articulada sobre a interioridade."

${ }^{31}$ Cf. G. DURAND, 1979, Les figures..., op. cit, p.248, "os românticos misturam sempre o prometeismo dos Enciclopedistas e o misticismo do Iluminismo", assim, o mito romântico é " um drama cuja resolução é o triunfo de um princípio: a morte de Satã".
} 
formas como as categorias de entendimento humanas deslizaram dos atos religiosos para ações racionais no mundo, contribuindo para isto o processo de subjetivação da figura tradicional de homem, e onde temporalidade cíclica da Tradição, doravante, torna-se prisioneira de eventos históricos, aparecendo apenas em momentos fugidios à consciência do coletivo social ${ }^{32}$.

Entretanto, resta lembrar alguns autores paradigmáticos que trataram de situar os estudos da memória para além dos ditames da Era moderna, na esteira de uma visão mais plena da figura do homem, e cujas proposições sempre serão lembradas nas diferentes reflexões de teoria antropológica sobre o devir. A lembrança dos ensinamentos destes mestres autoriza a própria memória das tradições e paradigmas antropológicos a se desvincularem da virulência de um positivismo e de um historicismo reducionistas.

A obra Maurice Halbwachs (1877-1945) é certamente aquela que, mesmo herdeira da linhagem da École de l'Année Sociologique, reina soberana em suas referências ao destino imemorial das sociedades humanas. Halbwachs, na aurora dos estudos antropológicos sobre memória, rompendo com a influência do bergsonismo, vai conferir ao Tempo um tratamento conceitual mais complexo e sofisticado. Apegado aos valores de reconciliação que a memória confere ao homem e ao mundo, Halbwachs, reconhece, nos jogos da memória individual e nos seus enquadramentos com a vida, os seus atributos de um fenômeno social, afastando-se, assim, do bergsonismo ao perceber a solidariedade entre o tempo e a matéria de seu conteúdo, e instalando os jogos da memória no real. Seguindo-se este autor, engendradas no interior do trajeto singular de consolidação do próprio corpo social, as estruturas espaço-temporais as quais são portadores os indivíduos e as sociedades humanas adquirem espessura inusitada.

Em primeiro lugar, poder-se-ia dizer, portanto, que é a partir de Halbwachs que o pensamento antropológico se reconcilia em parte, com a "figura do homem da tradição", pois segundo seu entendimento a lembrança do passado não é ato individual de recordar, mas o resultado de laços de solidariedade. Em segundo, a memória, seguindo-se a sua inspiração, possui uma dimensão intangível, porque simbólica, pelo segredo que carrega a conformação da tradição de uma coletividade, uma vez que carrega consigo a dimensão profunda de seus mitos, lendas e crenças arranjadas no

\footnotetext{
${ }^{32}$ Cf. DIAS DUARTE. 1983: 35, “A imortalidade se desloca do eixo da preservação e cultivo da pessoa cognitiva para o da pessoa moral que se deveria justamente premiar na reintegração positiva na divindade após a morte".
} 
tempo, as quais configuram as práticas ordinárias de seus grupos e atores sociais.

Em Halbwachs, as noções de tempo e espaço são estruturantes dos quadros sociais da memória, ambas as instâncias solidárias entre si, fundamentais para a rememoração do passado na medida em que as localizações espaciais e temporais das lembranças são a essência da memória ${ }^{33}$. Nada escapa, nem mesmo a memória, a esta trama de consolidação das estruturas espaço-temporais que configuram a existência social uma vez que é da combinação dos seus diversos elementos, através da linguagem, que pode emergir a lembrança das memórias individuais. ${ }^{34}$

O pensamento do autor almeja uma definição mais sofisticada das estruturas espaço-temporais na configuração das sociedades humanas, no seu interior o Tempo não sofre de reducionismo, uma vez que tais estruturas abrem espaço para a compreensão da geografia fantástica que encerram dos trabalhos da memória. Halbwachs reconhece, de muitos modos, a vibração do tempo no conteúdo material das lembranças, atribuindo à memória o princípio“intencional" e "imaterial” de uma coordenação entre as diferentes temporalidades e as regiões do espaço em que se produzem, visto serem as lembranças solidárias das regiões da experiência social, as quais, por sua vez, lhe são irredutíveis. ${ }^{35}$

Em Halbwachs frutifica o diálogo com a física einsteinianna ${ }^{36}$, e, através dele o pensamento antropológico rompe com a idéia distorcida do tempo associado à extensão da matéria. Ao contrário, do que vinha sendo anunciado o Tempo revela-se cada vez mais como duração, preenchido por falhas e lacunas, fenômeno que reflete o arranjo da matéria pela vida, o que lhe permite referir que a memória, na linha do que afirmará Bachelard, posteriormente, é tributária da sinergia de múltiplas causalidades, tanto formal quanto material, e onde o fluxo temporal contínuo da consciência, proposto pelo bergsonismo se esvanece ${ }^{37}$.

A partir de Halbwachs, poder-se-ia dizer que o pensamento antropológico se

\footnotetext{
33 Cf. HALBWACHS 1968, o "esforço de rememorização cria um espaço e um tempo específicos”, tal esforço significa que os sujeitos que lembram tempos e espaços singulares, os quais são da ordem da vivência. Trata-se, segundo o autor, da memória coletiva resgatada sobre acontecimentos vividos.

34 Através da memória coletiva compreende-se uma relação diferencial, "a sucessão de eventos individuais que resulta nas mudanças que se produzem nas nossas relações com os grupos os quais somos misturados e das relações que se estabelecem entre os grupos", cf. os comentários pertinentes de J. DUVIGNAUD, em seu prefácio à obra de M. HALBWACHS, Mémoire Collective. Paris, PUF, 1968: XII.

${ }^{35}$ Ver à propósito, os comentários de G. DURAND, 1984, op. cit, em particular à obra de M. Halbwachs, La Topographie légendaire des évangiles en Terre sainte, Paris, PUF, 1941, apud.

${ }^{36}$ Cf. J. DUVIGNAUD, "Préface". In. M. HALBWACHS, op. cit. P. XI.

${ }^{37}$ O belíssimo trabalho de Bosi, 1987, explorando o fértil pensamento de Halbwachs, nos revela a força da memória como ato de restaurar no presente as lembranças do passado, uma vez que lembrar não é reviver algo preservado do passado, mas é refazer, reconstruir, repensar com as idéias de hoje as experiências do passado.
} 
reconcilia em parte, com a "figura do homem da tradição", pois segundo seu entendimento a lembrança do passado não é ato individual de recordar, mas o resultado de laços de solidariedade ${ }^{38}$. Contemplar a memória significa reconhecer a força intangível das motivações simbólicas que regem as ações da inteligência humana, o que significa que não se pode ignorar, nos seus arranjos, o espaço de figurações de utopias coletivas diferenciadas. Neste sentido, a memória não se configura apenas num tradicionalismo de cunho nostálgico e sentimental, mas nos mitos, saberes, fazeres e tradições que são perenizados, ordinariamente, no interior das manifestações culturais humanas, a contragosto das intimações objetivas de um devir, "numa seqüência de fixações no espaço da estabilidade do ser". ${ }^{39}$

Da mesma forma, as ações discursivas que o próprio antropólogo faz acerca da memória enraízam-se no espaço dos mitos e das crenças da sociedade e do grupo social ao qual pertence. ${ }^{40}$ Voltando-se progressivamente as costas à dimensão intangível que configura a memória coletiva, social ou individual, o que resta para os estudiosos da memória no mundo contemporâneo, é a nostalgia das imagens: o fim das guerras, do fim das lutas, do fim dos tempos.

Como ensinam os estudos da cultura ocidental faustiana, nos dias atuais, a memória guarda sua expressão intangível em cidades mundiais que se exteriorizam, como obra da consolidação do próprio Tempo, numa expansão infinita. Portanto, o estudo da memória, nos dias de hoje e sempre, não escapa à sua relação intima com a inteligibilidade dos símbolos e mitos criados pelas sociedades humanas. E mesmo quando, através da memória, se busca capturar a própria linguagem de símbolos que constitui a própria ação humana no mundo, ela, a memória, nutre-se, ainda assim, da sua expressão intangível: o sentimento de anti-destino.

À disposição de todos, a memória autoriza, assim, não só conflito de liberdades e sua afirmação, mas as trocas sociais e simbólicas que nela existem, e onde a consciência, seja coletiva seja individual, se consolida na sobreposição de diferentes

\footnotetext{
38 A respeito, ver os comentários de E. BOSI Memória e sociedade. Lembranças de velhos. São Paulo, Queiroz ED. Ltda. e EDUSP, 1987 pp. 17- 22, sobre o pensamento de Halbwachs quando afirma que este autor "amarra a memória da pessoa à memória do grupo, e esta última à esfera maior da tradição, que é a memória coletiva de cada sociedade", Segundo BOSi, rememorações cotidianamente construídas na dinâmica da vida pelo instrumento decisivamente socializador da memória: a linguagem pela qual se comunica o pensamento.

${ }^{39}$ Cf. G. DURAND, 1984, op. cit.

${ }^{40}$ Sugere-se aqui leituras tão diversas como HOBSBAWN, Eric \& RANGER, Terence. A invenção das tradições. Rio de Janeiro, Paz e Terra, 1984, HOUTART, François e LEMERCINIER, Geneviève. De la perception de la durée à la construction du temps. Louvain, U.C.L: Centre de Recherches socioreligieuses, 1986 e JEUDY, Henri-Pierre. Mémoires du Social. Paris, P.U.F., 1986.
} 
esquemas de pensamento e linguagens. Habitar o espaço da memória, assim, é conviver com memórias coletivas, individuais e sociais negociadas e processuais, e não, simplesmente, domesticar um território vazio e opaco, lugar de reativação de tradições perdidas ou da nostalgia do passado. Isto porque, cada vez mais, o estudo da memória ensina, a todos que com ela operam, uma repulsa a um pensamento que separa o "eu" que pensa da compreensão daquilo que é pensado, pois, no limiar da memória há, sempre e eternamente, uma elaboração ética progressiva da vida social e uma projeção de figura de homem.

\section{BIBLIOGRAFIA}

BENJAMIN, Walter. "Sobre alguns temas em Baudelaire". In: Charles Baudelaire um lírico no auge do capitalismo. Obras escolhidas volume III. SP, Ed. Brasiliense, 1990. BERGSON, Henri. Matéria e Memória. S.P. Martins Fontes, 1990.

BOLLE, Willi. Fisiognomia da Metrópole Moderna; representação da história em WalterBenjamin. São Paulo, Ed. USP, 1994.

BORELLI, Silvia Helena Simões. "Memória e temporalidade: diálogo entre Walter Benjamin e Henri Bergson". In: Revista Margem. Faculdade de Ciências Sociais - PUC - SP, 1992. BOSI, Ecléa. Memória e sociedade. Lembranças de velhos. São Paulo, Queiroz ED. Ltda. e EDUSP, 1987.

CASSIRER, E. "O mundo humano do espaço e do tempo”, In: Ensaio sobre o homem, introdução a uma filosofia da cultura humana. São Paulo, Martins Fontes, 1994.

DIAS DUARTE, Luiz Fernando. A Construção Social da Memória Moderna. In "Três ensaios sobre pessoa e modernidade". In: Boletim do Museu Nacional, nova série, Rio de Janeiro, Antropologia, $\mathrm{n}^{\circ}$ 41, agosto de 1983.

DOSSE, François. "Paul Ricoeur revoluciona a escrita da história"; In: Revista Margem, Temporalidades. Faculdade de Ciências Sociais - PUC, SP, 1996, número 5.

DURAND, Gilbert. Science de l'homme et tradition. Paris, Berg International Editeurs, 1979.

DURAND, Gilbert. Les structures anthropolgiques de l'imaginaire. Paris, Duond, 1984.

DURAND, Gilbert. Figures mythieus et visages de l'ouvre. Paris, Berg International, 1979.

ELIADE, Mircea. "A regeneração do tempo" IN: Mito do Eterno Retorno. SP, 
Mercuryo, 1992. P. 55 a 88.

ELIAS, Norbert. Du temps. Paris, Fayard, 1996 ou Über die Zeit. 1984.

EVANS-PRITCHARD, E.E. Os Nuer. São Paulo, Perspectiva, 1978.

GEERTZ, Clifford. "Pessoa, tempo e conduta em Bali" In: A interpretação das culturas. Rio de Janeiro, Zahar, 1978. 321 p.

GURVITCH, G. La multiplicité des temps sociaux. Paris, Cours de la Sorbonne, 1961. HALBWACHS, Maurice. Mémoire Collective. Paris, P.U.F., 1968. 204 p.

HOBSBAWN, Eric \& RANGER, Terence. A invenção das tradições. Rio de Janeiro, Paz e Terra, 1984.

HOUTART, François e LEMERCINIER, Geneviève. De la perception de la durée à la construction du temps. Louvain, U.C.L: Centre de Recherches socio-religieuses, 1986. JEUDY, Henri-Pierre. Mémoires du Social. Paris, P.U.F., 1986. 171 p.

LE GOFF, J. NORA, P. 'Les lieux de la mémoire" (volumes 1, 2,3). Paris, Gallimard. Diversos volumes.

LE GOFF, Jacques. História e memória. Campinas, ED. UNicamp, 1990.

NAMER, Gérard. Mémoire et Société. Paris, Méridiens Klincksieck, 1987. 242 p.

POLLAK, Michael. "Memória, esquecimento, silêncio" In: Estudos Históricos 3, Memória. Rio de Janeiro, vol. 2, n. 3, 1989, p. 3 a 15.

PUCELLE, J. Le temps. Paris, Presses Universitaires de France, 1955. 105 p. (115 P $977 \mathrm{t})$

RICOEUR, P Tempo e Narrativa. Volumes I, I e III. São Paulo, Papirus, 1994.

RICOEUR, P. et alii. El tiempo y las filosofías. Paris, Unesco/ Salamanca, Ediciones Sígueme, 1979.

SAHLINS, Marshall. Ilhas da Historia. Rio de Janeiro, Jorge Zahar, 1990.

SANTOS, Myrian. "O pesadelo da amnésia coletiva, um estudo sobre os conceitos de memória, tradição e traços do passado." In Revista Brasileira de Ciências Sociais, n 3, ano 8, outubro de 1993, ANPOCS 23.

THOMPSON, Paul. A voz do passado. Historia Oral. Rio de Janeiro, Paz e Terra, 1992. WHITROW, G.J. “O tempo na história, concepções do tempo da pré-história aos nossos dias". Rio de Janeiro, Jorge Zahar, 1993.

ZONABEND, Françoise. La mémoire longue. Temps et histoires au village. Paris, PUF, 1980. 